\title{
Reekspansiyon Pulmoner Ödem
}

\author{
Reexpansion Pulmonary Edema
}

\author{
Yasemin Işık, Ismail Katı, Onur Palabıyık, Uğur Göktaş \\ Yüzüncü Yıl Üniversitesi Tıp Fakültesi Anesteziyoloji ve Reanimasyon Anabilim Dalı, Van, Türkiye
}

\section{ÖZET}

Reekspansiyon pulmoner ödem; plevral efüzyon, pnömotoraks veya atelektaziye sekonder kollabe akciğerin tedavisi sırasında gelişen nadir ancak ölümcül olabilen bir komplikasyondur. Hipertansiyon, kalp yetersizliği, serebrovasküler hastalık ve diabetes mellitusu olan tek taraflı torasentez yapıldıktan 3 saat sonra reekspansiyon pulmoner ödem gelişen 68 yaşındaki olguyu sunduk. (Türk Yoğun Bakım Derneği Dergisi 2011; 9: 26-9)

Anahtar Kelimeler: Reekspansiyon akciğer ödemi, plevral efüzyon

\section{SUMMARY}

Reexpansion pulmonary edema is a rare but life threating complication which is occurring during the treatment of lung collapse secondary to pleural effusion, pneumothorax or atelectasis. We presented a 68 year-old case with hypertension, heart failure, cerebrovascular disease and diabetes mellitus who had developed reexpansion pulmonary edema three hours after the application of unilateral thoracentesis. (Journal of the Turkish Society of Intensive Care 2011; 9: 26-9) Key words: Reexpansion pulmonary edema, pleural effusio

Yazışma Adresi/Address for Correspondence: Dr. Yasemin Işık, Yüzüncü Yı Üniversitesi Tıp Fakültesi Anesteziyoloji ve Reanimasyon Anabilim Dalı, Van, Türkiye Tel.: +90 43221504 74- 6067 Gsm: +90 5326412380 E-posta: yaseminmd@yahoo.com Geliş Tarihi/Received: 02.03.2011 Kabul Tarihi/Accepted: 12.05 .2011

Türk Yoğun Bakım Derneği Dergisi, Galenos Yayınevi tarafından basılmıştır. / Journal of the Turkish Society of Intensive Care, published by Galenos Publishing. ISNN: 1300-5804 


\section{Giriş}

Reekspansiyon pulmoner ödem (RPÖ) uzun süre kollabe kalmış akciğerin tedavisi sonrasında gelişen nadir görülen bir komplikasyondur. Pulmoner kollapsın 72 saatten uzun olması RPÖ için en önemli risk faktörüdür. RPÖ, asemptomatik olgulardan koma ve ölüme kadar giden ciddi klinik tablolara yol açabilmektedir. Insidansının \%0,2-14 arasında olduğu bildirilmiş $(1,2)$ olup mortalitesi \%20'ye ulaşabilir (3). Erken tanı ve tedavi hayat kurtarıcıdır.

Bu sunuda 68 yaşında, tek taraflı torasentez yapıldıktan 3 saat sonra reekspansiyon pulmoner ödem gelişen olgu irdelenecektir.

\section{Olgu}

GIS perforasyonu nedeniyle acil operasyona alınan 68 yaşında bayan olgu, postoperatif 10. günde kardiyak arrest sonrası entübe edilip anestezi yoğun bakım ünitesine (YBÜ) alındı. Anamnezinde hipertansiyon, kalp yetersizliği, serebrovasküler hastalık ve diabetes mellitus hikayesi bulunan olgunun fizik muayenesinde kalp aritmik, kalp atım hızı (KAH): 65 atım/dk, kan basıncı (KB): 175/65 $\mathrm{mmHg}, \mathrm{SpO}_{2}$ : \%90 (SIMV, $\left.\mathrm{F}_{j} \mathrm{O}_{2}: 0,5\right)$, santral venöz basınç (SVB): $3 \mathrm{cmH}_{2} \mathrm{O}$, solunum sesleri sağda azalmış, batın distandü idi. Hipoksemiye bağlı beyin ödemi gelişen hastaya beyin ödemi ve mevcut hastalıklarına yönelik medikal ve destek tedavisi uygulandı. YBÜ'de yatışının 15. gününden itibaren sağ tarafta hafif plevral effüzyon gelişen olguya (Resim1) medikal tedaviye başlandı. Olgunun onkotik basıncı $17 \mathrm{cmH}_{2} \mathrm{O}$ ve albümini $2 \mathrm{~g} / \mathrm{dL}$ olması nedeni ile albümin (200 ml \%20) ve kolloid solüsyonu (1000 mL/gün) 3 gün, daha sonraki günlerde onkotik basınç bakılarak kolloid solüsyonu 500 mL/gün verilerek diürez sağlandı. YBÜ'de genel durumu orta, şuuru açık, trakeostomili PSV modunda (havayolu basıncı $15 \mathrm{cmH}_{2} \mathrm{O}$,

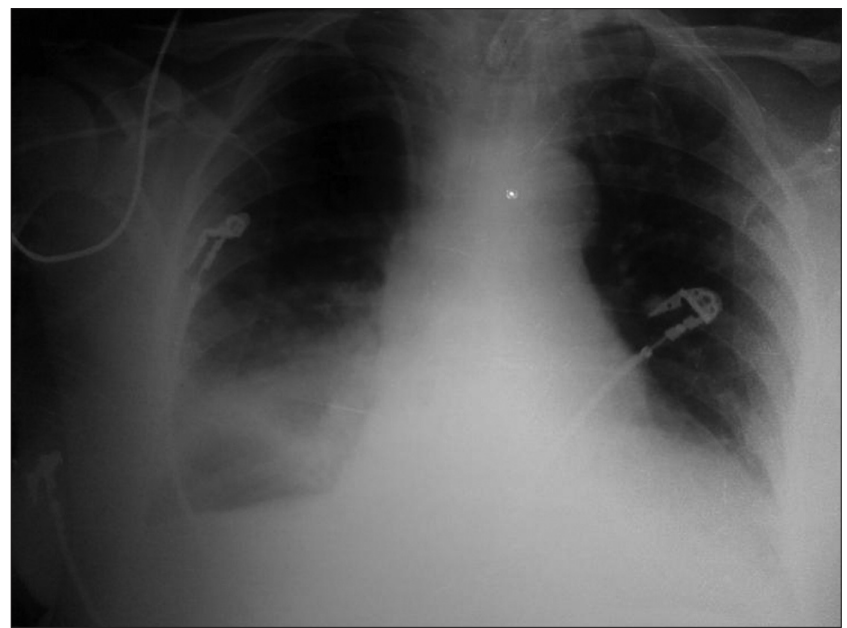

Resim 1. Torasentez öncesi akciğer grafisi
TV: 450 mL) mekanik ventilatöre bağlı olarak takip edildi. Sorunsuz takip edilen olgunun vital bulguları; KAH:115 atım/dk, KB: 150/85 mmHg, SpO 2 \% 97 (PSV, FiO2:0,5.), SVB: $8 \mathrm{cmH}_{2} \mathrm{O}$, ateş $37,4{ }^{\circ} \mathrm{C}$ idi. 25. günde SVB: 7 $\mathrm{cmH}_{2} \mathrm{O}$, kolloid basınç $22 \mathrm{cmH} 2 \mathrm{O}^{\prime} y a$ ulaşmasına ve diürez sağlanmasına karşın effüzyonda ve havayolu basınçların da artış ( $25 \mathrm{cmH}_{2} \mathrm{O}$ ) ve tidal volümde (TV: $370 \mathrm{~mL}$ ) azalma olması üzerine göğüs cerrahisi bölümü tarafından tüp torakostomi uygulandı. Torasentez ile tek seansta 1000 mL'den fazla sıvı boşaltıldı (Resim 2). Torasentez uygulamasından yaklaşık 3 saat sonra olguda solunum sayısında artış, fışkırır tarzda pembe köpüklü akciğer sekresyonu, siyanoz ve kusma görüldü. Fizik muayenesinde ral, ronkus mevcuttu, $\mathrm{SpO}_{2}: \% 42$, nabız:75 atım/dk ve TA: $105 / 50$ mmHg idi. Olgu IPPV moduna alındı. $\mathrm{FiO}_{2}: 1.0$ olacak şekilde $10 \mathrm{~cm} \mathrm{H}$ O PEEP uygulandı. Diüretik, steroid, sedatif, morfin i.v. verildi ve olgu lateral pozisyona çevrildi. Yarım saat sonra yapılan fizik muayenede hastanın hava yolu basınçlarının düştüğü, satürasyonun

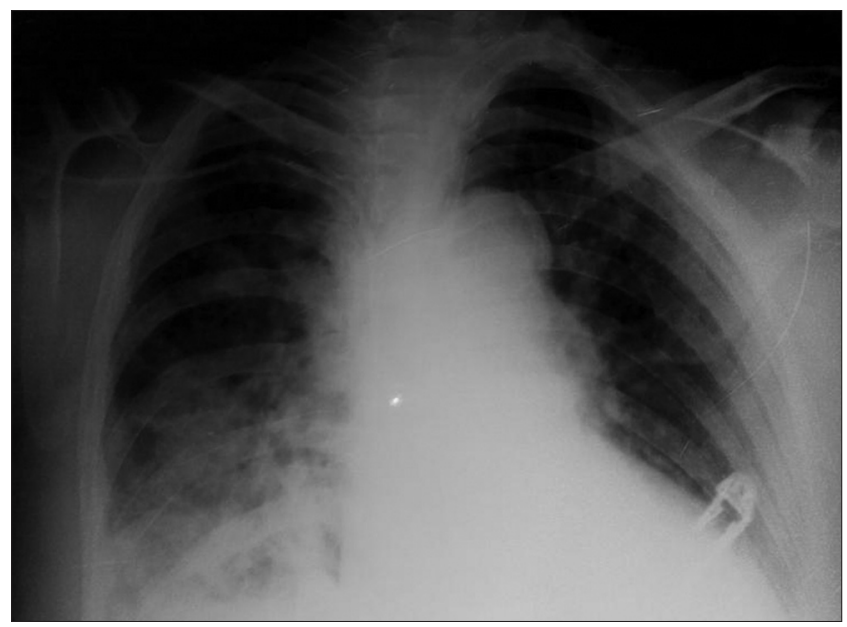

Resim 2. Torasentez sonrası akciğer grafisi

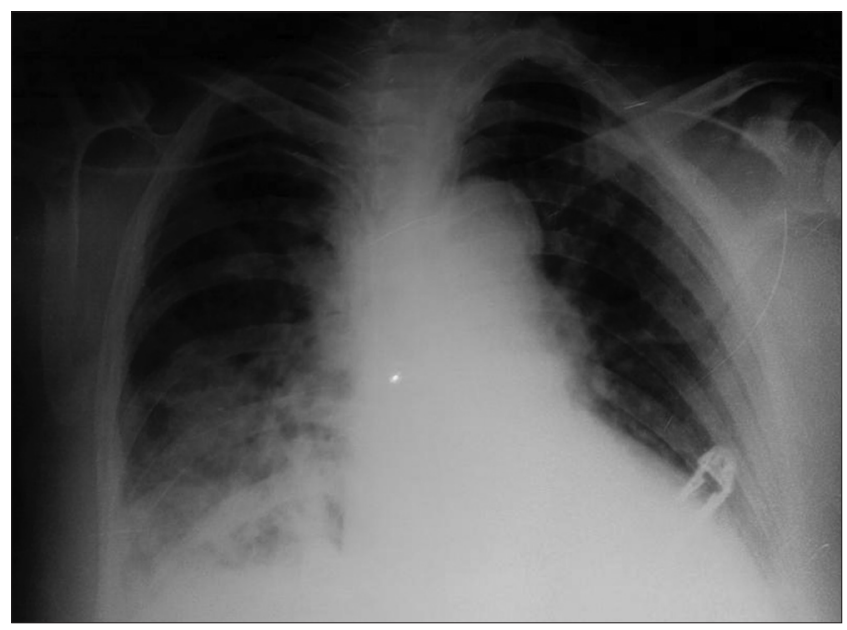

Resim 3. Reekspansiyon pulmoner ödem akciğer grafisi 
$\mathrm{FiO}_{2}: 50$ ve $\mathrm{SpO}_{2} \% 92$ olduğu ve kan gazı değerleri ise $\mathrm{pH}:$ 7.32, $\mathrm{PO}_{2}: 69 \mathrm{mmHg}, \mathrm{PCO}_{2}: 55 \mathrm{mmHg}, \mathrm{SpaO}_{2}$ : \%92, HCO3: 28 mEq/L, BE: (+1) idi. Olgunun PA akciğer grafisinde akciğer ödemi ile uyumlu sağ bazalde konsolidasyon ve orta zonda interstisyel infiltrasyon görüldü (Resim 3). Olguda gelişen akciğer ödeminin tek taraflı olması ve gelişme zamanı dikkate alınarak RPÖ olduğuna karar verildi. RPÖ gelişiminden 12 saat sonrasında olgu, solunumu rahatlayarak mekanik ventilasyondan ayrıldı ve $T$ piece'e alındı. PA akciğer grafisinde konsolide alanın ve infiltrasyonların azaldığı görüldü (Resim 4).

Mevcut hastalıklarından dolayı olgunun YBÜ'nde takip ve tedavisi devam etmektedir.

\section{Tartışma}

RPÖ, akciğerde uzun süreli kollapsa neden olan lezyonun tedavisi sırasında ortaya çıkan ender görülen bir komplikasyondur. Genellikle sıvı hava ve atelektaziye sebep olan lezyonun uzaklaştırılması sonrası görülür. Patofizyolojisi tam olarak bilinmemekle beraber eş zamanlı birden çok faktörün bir araya gelmesiyle oluşmaktadır $(3,4)$. 72 saatten uzun süren pulmoner kollapsı takiben hızlı akciğer ekspansiyonunun; pulmoner vasküler geçirgenlikte artışa, sürfaktan kaybına ve serbest oksijen radikallerinin oluşumuna neden olması patofizyolojide enflamatuvar reaksiyonların varlığını düşündürmektedir $(4,5)$. Kapiller geçirgenlik ve hidrostatik basınç artışı alveollere ve interstisyuma yüksek protein içerikli sıvı akışına, dolayısıyla ödem tablosu gelişimine neden olmaktadır $(4,6)$.

Yücel ve ark. (7) çalışmalarında RPÖ mekanizmasını akciğerin mikrovasküler geçirgenliğindeki belirgin artış şeklinde açıklamışlar ve bunu da 2 mekanizmaya bağlamışlardır. Birincisi aşırı gerilme ile alveol duvarının mekanik tahribi ikincisi ise diğer organlarda meydana gelen iskemi reperfüzyon hasarıdır. Akciğer reperfüzyonu sırasın-

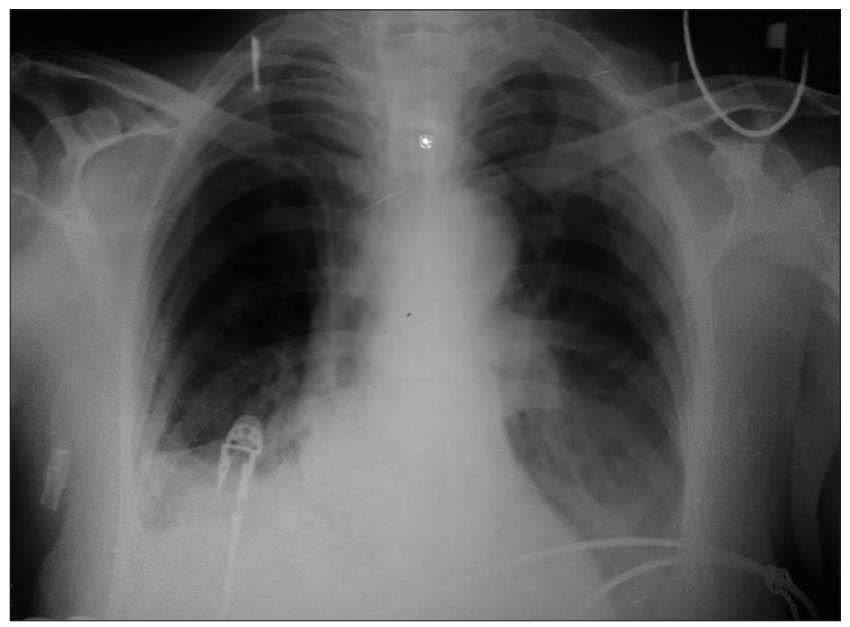

Resim 4. Tedaviden 12 saat sonraki akciğer grafisi da endotel zedelenmesine sebep olan serbest radikaller, lipid ve polipeptit mediyatörler olup bunlara bağlı vasküler geçirgenlikte artma meydana gelir.

RPÖ için pulmoner kollapsın 72 saatten uzun olmasının en önemli risk faktörü olmakla birlikte yüksek miktarda mayinin hızlı drenajı (>1500 ml), bronşiyal obstrüksiyon, reekspansiyon teknikleri, bronkoskopi sırasında trakeobronşiyal ağacın aşırı yüksek volümle aspirasyonu, pulmoner arter basınç değişiklikleri, sürfaktan kaybı, büyük ekstratorasik kitlelerin basınç etkisinin ortadan kaldırılması ve tek akciğer ventilasyonu gibi faktörler RPÖ için risk faktörlerini oluşturmaktadır $(2,5,8)$. Ayrıca Matsuura ve ark. (2) yaptıkları çalışmada genç yaş grubunda RPÖ gelişimi için riskin daha fazla olduğunu belirtmişlerdir.

RPÖ'de ilk bir saat \%64 oranında asemptomatiktir. $(3,5)$ Semptomlar genellikle reekspansiyondan sonra iki saat içinde görülmekle birlikte 24-48 saat sonra da gelişebilmektedir (4). Asemptomatik veya minimal olguların sadece radyolojik bulgular verdiği, diğer yandan hipoksi, hemodinamik instabilite ve ölüm gibi ciddi klinik durumların gelişebileceği bildirilmiştir (4). Reekspansiyondan birkaç saat sonra devamlı öksürük, taşikardi, takipne, hipoksemi, ral, bol köpüklü sekresyon ekspektorasyonu meydana gelmektedir. Klinik olarak 1-2 gün içerisinde sonlanabileceği gibi 5-7 güne kadar sürebilmektedir $(3,4)$. RPÖ genellikle kollabe olan akciğerde meydana gelmesine rağmen nadiren kontralateral akciğerde de görülebilmektedir. Bundan dolayı histamin ve prostaglandin gibi vazoaktif maddelerin veya nörojenik faktörlerin de RPÖ gelişiminde etkili olabileceği düşünülmektedir $(5,9)$. Mortalite oranı bilateral ve ani başlayan olgularda artmakla birlikte yaklaşık \%20 olarak bildirilmektedir $(3,6)$. Erken tanı ve tedavi yaklaşımı hastalığın progresyonunu belirler ve hayat kurtarıcıdır $(4,6)$. Olgunun; yaklaşık 10 günlük bir akciğer kollabsına neden olan plevral effüzyon sonrası gelişmesi, torasentezle tek seansta yaklaşık 1000 mL'den fazla sıvı boşaltılması, pulmoner ödemin torasentezden yaklaşık 3 saat sonra gelişmesi, PA akciğer grafisinde torasentez uygulanan akciğer tarafında infiltrasyon artışının varlığı ve klinik bulguların mevcudiyeti bize RPÖ’yü düşündürdü.

RPÖ tedavisi bir takım kombine yaklaşımları içermektedir. Oksijen desteği, invaziv veya non invaziv ventilatör desteği, vazopressör ve/veya inotropik ajanlar, dikkatli diürez, steroidler, sedatifler, sıvı alımının kesilmesi uygulanan medikal tedavi yaklaşımlarıdır (3-6) Etkilenen kısım yukarıda kalacak şekilde lateral dekübit pozisyonun verilmesi arteriyovenöz şantın azaltılması ve oksijenizasyonun artırılmasında faydalıdır. Sürekli pozitif hava basıncı (CPAP) uygulanmasıyla da başarılı sonuçlar bildirilmiştir. Bununla birlikte bazı antiinflamatuvar ilaçlar, prostaglandin analogları ve interlökin-8'in hastalığın ilerleyişini yavaşlattığı tespit edilmiştir (10). Olgumuza da benzer şekilde IPPV modunda $\mathrm{FiO}_{2}: 1.0$ olacak şekilde $10 \mathrm{~cm} \mathrm{H} \mathrm{H}_{2} \mathrm{O}$ PE- 
EP uygulandı. Diüretik, steroid, sedatif, morfin iv verildi ve lateral pozisyona çevrildi. Bir kaç saat içerisinde semptomlar gerileyerek olgunun kliniği düzeldi.

Sonuç olarak risk faktörleri mevcut olgularda hava ya da sıvı drenajının düşük negatif basınçla ve aralıklı yapıması ve her bir drenajın 1000 cc'yi geçmemesi gibi uygulamalarla gelişmesi önlenebilir olan RPÖ'de hızlı tanı ve agresif tedavinin hayat kurtarıcı olduğu unutulmamalıdır.

\section{Kaynaklar}

1. Feller-Kopman D, Berkowitz D, Boiselle P, Ernst A. Large-Volume Thoracentesis and the Risk of Reexpansion Pulmonary Edema. Ann Thorac Surg 2007;84:1656-62.

2. Matsuura $Y$, Nomimura $T$, Murakami $H$, Matsushima T, Kakehashi $\mathrm{M}$, Kajihara $\mathrm{H}$. Clinical analysis of reexpansion pulmonary edema. Chest 1991:100:1562-6.

3. Dias OM, Teixeira LR, Vargas FS. Reexpansion pulmonary edema after therapeutic. Thoracentesis. Clinics (Sao Paulo) 2010:65:1387-9.
4. Stawicki S.P, Sarani B, Braslow BM. Reexpansion pulmonary edema. OPUS 12 Scientist 2008:2:29-31.

5. Sohara Y. Reexpansion pulmonary edema. Ann Thorac Cardiovasc Surg 2008;14:205-9.

6. Yücel O, Erdoğu V, Kavaklı K, Genç O, Turhan K. Reekspansiyon pulmoner ödemi: Olgu sunumu. Turkish J Thorac Cardiovasc Surg 2009;17:218-20.

7. Yucel O, Uçar E, Tozkoparan E, Gunal A, Akay C, Sahin MA, et al. Proanthocyanidin to prevent formation of the reexpansion pulmonary edema. J Cardiothorac Surg 2009;4:40.

8. Kim YK, Kim H, Lee CC, Choi HJ, Lee KH, Hwang SO, et al. New classification and clinical characteristics of reexpansion pulmonary edema after treatment of spontaneous pneumothorax. Am J Emerg Med 2009;27:961-7.

9. Takamura K, Takamura M, Kobayashi H. [Current topics on re-expansion pulmonary edema]. Kokyu To Junkan 1984;32:133-41.

10. Nakamura M, Fujishima S, Sawafuji M, Ishizaka A, Oguma T, Soejima K, et al. Importance of interleukin-8 in the development of reexpansion lung injury in rabbits. Am J Respir Crit Care Med 2000:161:1030-6. 